\title{
Agrobacterium tumefaciens Conn
}

\author{
III. Effect of Thermal Shock on Bacteria in Relation to \\ Tumor-Inducing Ability \\ TOM STONIER, ROBERT E. BEARDSLEY, LOWELL PARSONS, AND \\ JAMES MCSHARRY \\ Laboratory of Plant Morphogenesis, Department of Biology, Manhattan College, Bronx, New York
}

Received for publication 1 September 1965

\begin{abstract}
Stonier, Tom (Manhattan College, Bronx, N.Y.), Robert E. BeardSLEy, Lowell Parsons, and James McSharry. Agrobacterium tumefaciens Conn. III. Effect of thermal shock on bacteria in relation to tumor-inducing ability. J. Bacteriol. 91: 266-269. 1966.-Bacteria heated to $42 \mathrm{C}$ for $30 \mathrm{~min}$ exhibit a decrease in tumorinitiating ability without a detectable loss in viability. The thermal shock inhibits subsequent bacterial growth for up to $1.5 \mathrm{hr}$. As bacterial growth recovers, so does tumor-initiating ability. Respiration of the culture is somewhat increased by the heat treatment. The data suggest that living, actively respiring bacteria do not induce tumors unless they are also growing. The results also point to the necessity for excluding bacterial growth inhibition when interpreting data on the effect of various agents on tumor initiation.
\end{abstract}

The manner in which the crown gall organism, Agrobacterium tumefaciens Conn, converts normal plant cells into tumor cells has remained a mystery since the demonstration by Braun and White that the tumor cells retain their morphogenetic autonomy even when the bacteria are no longer present $(6,14)$. The nature of the hypothetical tumor-inducing principle released by the bacteria has remained a matter for speculation (for reviews, see 3, 5, 8).

The concept that the tumor-inducing principle is heat-labile was suggested by Braun and Mandle (4), who stated that "inactivation of the tumorinducing principle itself occurs at $32 \mathrm{C}$." In a subsequent publication, Braun (1) reported that between 27.5 and $28.8 \mathrm{C}$ there was a progressive decrease in the size and weight of the resulting tumors and a delay in the inception period. Tumors were not observed above $29 \mathrm{C}$. Calculations of the activation energy implied values of the order of $80 \mathrm{kcal} / \mathrm{mole}$. Braun interpreted the results to suggest that "either the tumor-inducing principle itself or something intimately associated with its inactivation is a factor of complex structure." This interpretation of the data was recently questioned by Lipetz (9), who provided evidence to indicate that the response of infected plants to temperature, in the range studied by Braun and Mandle, may reflect effects on the host rather than inactivation of a specific tumorinducing principle.
More recently, Lippincott and Lippincott (11) demonstrated that bacteria exposed to heat treatment lose, in part, their ability to produce tumors, without a loss in viability. This finding is of considerable interest, especially in view of the fact that the "results suggest that a first-order, unimolecular event is responsible for the loss of TIA [tumor-initiating ability]." These authors calculated a heat of inactivation of $56.7 \mathrm{kcal} /$ mole and suggested further that a "particular protein or nucleoprotein active in the process of infection may be inactivated by the treatment."

The results presented here confirm the observation of the Lippincotts that bacteria exposed to temperatures in the range 39 to $45 \mathrm{C}$, for periods of less than $1 \mathrm{hr}$, exhibit a decrease in tumorinitiating ability without a detectable loss in viability. Our results extend this finding to indicate that the effect of $42 \mathrm{C}$ on the tumor-initiating ability of the bacteria is transient and nonspecific in respect to the tumor-initating process, insofar as the thermal shock temporarily inhibits bacterial growth.

\section{Materials AND Methods}

All experiments were conducted with strain B6 of A. tumefaciens growing, and treated, in media described by Lippincott and Heberlein (10). Viability counts were obtained in the standard manner by dilution and plating on agar plates (7). Samples and dilution tubes were agitated with a Vortex mixer to reduce 
clumping. The tumor-initiating ability of the bacteria was assayed against pinto bean leaves according to the technique described by Lippincott and Heberlein (10). Respiration was measured by following oxygen uptake in a Warburg vessel (12), and by following the reduction of methylene blue in an atmosphere of nitrogen (13). In both instances, the bacterial cultures were supplemented with $0.02 \mathrm{M}$ sucrose in addition to the $0.5 \%$ sucrose initially present in the growth medium. All phases of the experiments except the thermal treatments were conducted at $27 \mathrm{C}$.

Temperature treatments consisted of immersion of shaking bottles (containing $30 \mathrm{ml}$ of bacterial cultures) for various periods of time in a hot-water bath kept at 42 C. Control cultures were immersed in a bath kept at 27 C. A 2-ml amount of sample was inoculated into $18 \mathrm{ml}$ of fresh medium immediately after thermal treatment, and growth was measured by following changes in turbidity with a Coleman Jr. spectrophotometer at $600 \mathrm{~m} \mu$.

\section{RESULTS}

We were able to repeat the observations of the Lippincotts, viz., that exposing the bacteria to $42 \mathrm{C}$ for up to $45 \mathrm{~min}$ resulted in no significant decrease in viability, but did result in an appreciable drop in the number of tumors induced on pinto bean leaves. We also observed that bacteria inoculated into fresh media at $27 \mathrm{C}$ after heat shock did not immediately resume growth as measured by increase in turbidity, but turbidity did increase after a lag. This lag increased with the length of time the bacteria were kept at $42 \mathrm{C}$ : a 30-min treatment caused increases in lag time varying from 45 to $90 \mathrm{~min}$ over controls. Figure

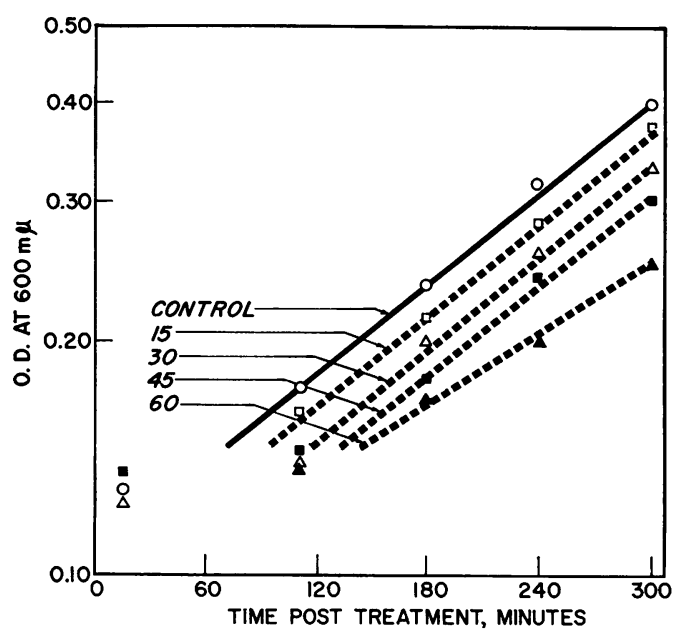

Fig. 1. Effect of thermal shock on growth of bacteria inoculated into fresh media at 27 C. Symbols: $O$, 27 C control; $\square, 42$ C for 15 min; $\triangle, 42 C$ for 30 min; , $42 C$ for 45 min; $\Delta, 42 C$ for 60 min. Note that heat damage is transient if the bacteria are returned to $27 \mathrm{C}$ in 45 min or less.

Lix

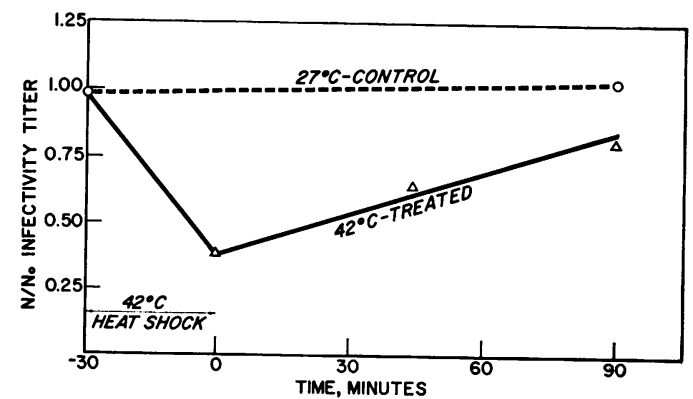

FIG. 2. Effect of thermal shock on tumor-initiating ability of bacteria. Symbols: $0,27 C$ control cultures; $\triangle$, cultures exposed to $42 \mathrm{C}$ for $30 \mathrm{~min}$. Note the recovery of tumor-initiating ability with time after treatment. (The $t+90$ point of the control in this experiment is based on 15 of 18 scored leaves, omitting three leaves which had formed tumors in excess of three times the mean value indicated.)

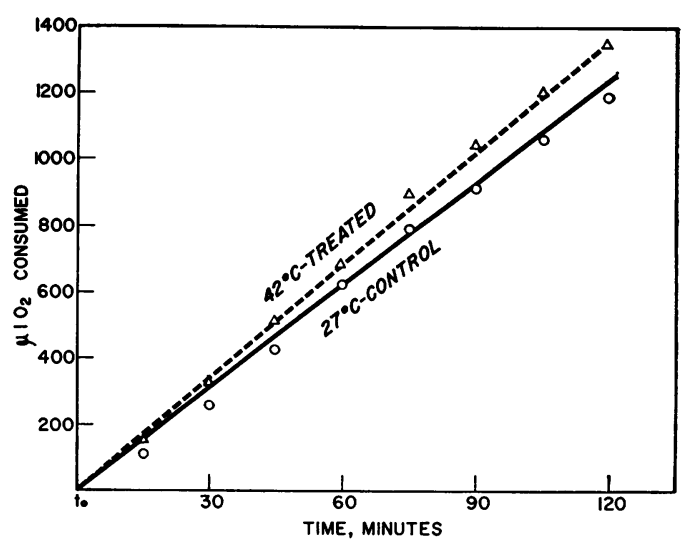

Fig. 3. Effect of thermal shock on oxygen uptake at $27 C$ by the bacteria. Symbols: $0,27 C$ control cultures; $\triangle$, cultures exposed to $42 C$ for $30 \mathrm{~min}$. Note that the oxygen uptake of $42 \mathrm{C}$-treated cultures is somewhat faster during the first $2 \mathrm{hr}$ after treatment.

1 shows the turbidity changes that folowed heat treatments in one experiment.

Assays for tumor-inducing ability were performed in two experiments and, although there were a few leaves which behaved erratically in the assays, the results were completely consistent. As is shown in Fig. 2, the number of tumors formed when bacteria were inoculated onto leaves immediately after exposure to $42 \mathrm{C}$ for 30 min was about $40 \%$ of the number formed prior to heat shock. This decrease is in agreement with that reported by the Lippincotts. However, the number of tumors formed returned to the initial value when leaves were infected $1.5 \mathrm{hr}$ after heat shock. At this time, bacterial growth had resumed its normal growth rate. The recovery of the original tumor-inducing ability, at about the same 
time that the bacteria entered log-phase growth, was observed in both experiments.

In view of the fact that the reduced efficiency in tumor initiation was correlated with a temporary cessation of growth, it was of interest to learn whether the heat-shocked bacteria respired at a slower rate than did controls. Figure 3 shows that respiration was somewhat increased by the thermal treatment, a fact also confirmed by observing the rate of reduction of methylene blue under anaerobic conditions.

\section{Discussion}

The temporary inhibition of growth, as evidenced by a lag period of up to $1.5 \mathrm{hr}$ after a 30-min incubation period at $42 \mathrm{C}$, would probably not show up as a reduction in tumor-initiating ability in most tumor assay systems available. The reduction in tumor-initiating ability apparently can be demonstrated in the pinto bean leaf assay system because the first few hours after infection constitute one of the critical periods in tumor initiation (10). It would appear either that some cells of young expanding pinto bean leaves are already in a "conditioned" state prior to, or immediately after, wounding, or that, unlike other systems, the bean leaf cells need not be "conditioned" to be altered by the bacteria into tumor cells. In other systems, wounding results in the presence of conditioned cells only after a lag of many hours $(2,9)$.

Although the assay system utilized by the Lippincotts may be atypical in relation to conditioning, it is the most useful system devised up to now for quantitatively assaying tumor initiation. It is, however, somewhat erratic because some leaves seem to form no tumors at all, whereas other individual leaves, on occasion, produce a superabundance of tumors. The $t+90$ point of the control in Fig. 2 would have been almost $50 \%$ above its indicated value if we had included 3 leaves (of 18) that had formed tumors in excess of three times the mean value indicated. The results should therefore be viewed with a certain amount of caution.

Given this qualification, however, and considering the fact that our results confirm the finding of Lippincott and Lippincott that the thermal treatment inhibits tumor-initiating ability without reducing viability, the data presented above imply that living, actively respiring bacteria do not induce tumors unless they are also growing. This illustrates the necessity for excluding inhibition of bacterial growth when interpreting data on the effect of agents on tumor initiation.

The results obtained in this study are consistent with the hypothesis that metabolic activity associ- ated with growth is essential for tumor initiation, but provide no information about the specific properties of the hypothetical tumor-inducing principle. Together with the findings reported by Lipetz (9), our data indicate that evidence presented so far suggesting tumor-initiating ability to be associated with a heat-labile agent of complex structure is subject to alternative explanations.

\section{ACKNOWLEDGMENTS}

This investigation was supported by Public Health Service Research Grants CA-06957 to Stonier, and CA-06956 to Beardsley. Parsons was supported by an Undergraduate Research Grant from the National Science Foundation. General support of the Laboratory of Plant Morphogenesis by Public Health Service Institutional Grant RC 1193, Damon Runyon Memorial Grant 710, and the Christine Sonntag Foundation for Cancer Research is also gratefully acknowledged. We are indebted to J. Lipetz, U. Naf, and J. Lippincott for reviewing the manuscript.

\section{Literature Cited}

1. Braun, A. C. 1950. Thermal inactivation studies on the tumor inducing principle in crown gall. Phytopathology 40:3.

2. BraUN, A. C. 1952. Conditioning of the host cell as a factor in the transformation process in crown gall. Growth 16:65-74.

3. BRAUN, A. C. 1962. Tumor inception and development in the crown gall disease. Ann. Rev. Plant Physiol. 13:533-558.

4. Braun, A. C., and R. J. Mandle. 1948. Studies on the inactivation of the tumor inducing principle in crown gall. Growth 12:255-269.

5. Braun, A. C., and T. Stonier. 1958. The morphology and physiology of plant tumors. Protoplasmatologia Ser. X-5a. Springer Verlag, Vienna.

6. Braun, A. C., AND P. R. White. 1943. Bacteriological sterility of tissues derived from secondary crown gall tumors. Phytopathology 33:85-100.

7. Heberlein, G. T., and J. A. Lippincott. 1965. Photoreversible ultraviolet enhancement of infectivity in Agrobacterium tumefaciens. J. Bacteriol. 89:1511-1514.

8. Klein, R. M., AND G. K. K. LinK. 1955. The etiology of crown-gall. Quart. Rev. Biol. 30:207-277.

9. LIPETZ, J. 1965. Crown gall tumorigenesis: effect of temperature on wound healing and conditioning. Science 149:865-867.

10. Lippincott, J. A., AND G. T. Heberlein. 1965. The induction of leaf tumors by Agrobacterium tumefaciens. Am. J. Botany 52:396-403.

11. Lippincott, J. A., AND B. B. LippincotT. 1965. Agrobacterium tumefaciens: thermal inactivation of tumor-inducing ability. Science 147: 1578-1579. 
12. Umbreit, W. W., R. H. Burris, and J. F. StaufFER. 1964. Manometric techniques, 4th ed. Burgess Publishing Co., Minneapolis.

13. Van Lanen, J. M., A. J. Riker, AND I. L. BaldWIN. 1952. The effect of amino acids and related compounds upon the growth, virulence, and activity of crown gall bacteria. J. Bacteriol. 63:723-734.

14. White, P. R., AND A. C. Braun. 1942. A cancerous neoplasm of plants. Autonomous bacteria-free crown-gall tissue. Cancer Res. 2:597617. 